\title{
G

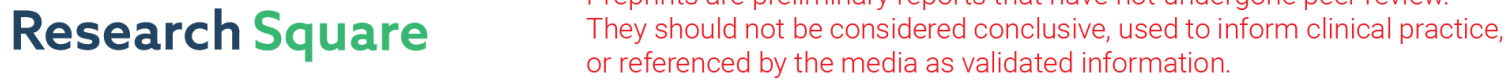 \\ Determinants of Health-related Quality of Life in Recently Detoxified Patients With Severe Alcohol Use Disorder
}

\section{Najlaa Lahbairi}

Normandie Univ, UNICAEN, PSL Université de Paris, EPHE, INSERM, U1077, CHU de Caen, GIP Cyceron Alice Laniepce

Normandie Univ, UNICAEN, PSL Université de Paris, EPHE, INSERM, U1077, CHU de Caen, GIP Cyceron

\section{Shailendra Segobin}

Normandie Univ, UNICAEN, PSL Université de Paris, EPHE, INSERM, U1077, CHU de Caen, GIP Cyceron Nicolas Cabé

Normandie Univ, UNICAEN, PSL Université de Paris, EPHE, INSERM, U1077, CHU de Caen, GIP Cyceron

Céline Boudehent

Normandie Univ, UNICAEN, PSL Université de Paris, EPHE, INSERM, U1077, CHU de Caen, GIP Cyceron

François Vabret

Normandie Univ, UNICAEN, PSL Université de Paris, EPHE, INSERM, U1077, CHU de Caen, GIP Cyceron

\section{Géraldine Rauchs}

Normandie Univ, UNICAEN, PSL Université de Paris, EPHE, INSERM, U1077, CHU de Caen, GIP Cyceron

Anne-Lise Pitel ( $\square$ anne-lise.pitel@unicaen.fr)

Normandie Univ, UNICAEN, PSL Université de Paris, EPHE, INSERM, U1077, CHU de Caen, GIP Cyceron

\section{Research Article}

Keywords: health-related quality of life, alcohol use disorder, cognition, sleep, anxiety, impulsivity

Posted Date: December 13th, 2021

DOl: https://doi.org/10.21203/rs.3.rs-1156296/v1

License: (1) This work is licensed under a Creative Commons Attribution 4.0 International License. Read Full License 


\section{Abstract}

Background. Health-related quality of life (HRQLL) is an important clinical outcome in Alcohol Use Disorder (AUD) and is considered as a relevant indicator of treatment success. While a better understanding of the factors affecting HRQoL would enable to adjust patients' care to favour treatment outcome, the determinants of HRQoL in AUD remain unclear. This study aims at describing HRQoL in AUD patients and at identifying its best predictors.

Methods. We included 53 recently detoxified patients with severe AUD (sAUD) and 38 healthy controls (HC). They underwent a cognitive assessment and filled in questionnaires concerning socio-demographics, alcohol history, sleep quality, depression, anxiety and impulsivity. Additionally, a HRQoL questionnaire especially designed for AUD patients (Alcohol Quality of Life Scale; AQoLS) was used.

Results. SAUD patients reported that alcohol affects their HRQoL mainly in the "negative emotions", "control", "relationships", and "sleep" domains. Compared to HC, they were impaired on episodic memory, working memory, executive functions, and processing speed tasks. They also reported lower sleep quality, higher depression, anxiety and impulsivity. No association was found between AQoLS total score and sociodemographics, cognitive performance, or sleep quality in patients. We found a significant correlation between HRQoL and depression/anxiety as well as impulsivity. Anxiety and impulsivity were indeed the only significant predictors of HRQoL, explaining $47.7 \%$ of the variance.

Conclusions. Anxiety and impulsivity are crucial determinants of HRQoL in recently detoxified SAUD patients. Since anxiety and impulsivity are frequent issues in addiction and especially in AUD, they should be particularly considered by clinicians to favour treatment outcomes.

\section{I - Introduction}

Alcohol Use Disorder (AUD) is among the most prevalent mental disorders worldwide (1). According to the World Health Organization's global status report on alcohol and health (2), an estimated 283 million people has AUD, with Europe showing the highest prevalence ( $8.8 \%$ of the adult population) followed by the US $(8.2 \%$ of the adult population). Abstinence has long been considered as the only final therapeutic goal for AUD (3). However, this clinical approach has a number of limitations: (i) only a few AUD patients seek treatment (4), (ii) among those who seek treatment, many patients report that they are not ready to completely stop drinking (5) and the risk of relapse remains high (6) even after a long period of abstinence (7) , and (iii) quantitative criteria based on the amount of alcohol consumed or the length of the abstinence period seem to be a weak indicator to evaluate the effectiveness of a treatment (8). For all these reasons, reducing alcohol consumption without necessarily aiming to achieve total abstinence is gaining an increasing interest in clinical practice. This novel strategy gives a crucial place to qualitative assessments. In this perspective, quality of life (QoL) has emerged as a new treatment outcome that is more adapted to patients' concerns. Indeed, QoL is considered to be not only a measure of treatment effectiveness (8) but also a motivational tool (9). Thus, improving QoL might be a primary endpoint in the management of AUD.

QoL is defined as "an individual's perception of his/her position in life, and in the context of culture and value system in which he/she lives, and also in relation to his/her goals, expectations, standards, and concerns" (10). 
In a biomedical context, the term health-related quality of life (HRQoL) has been proposed (11), referring to "the patient's subjective perception of the impact of his/her disease and its treatment(s) on his/her daily life, physical, psychological and social functioning and well-being (12). HRQoL is known to be more robust, highly sensitive to change (10) and more relevant for evaluating the effectiveness of a treatment than QoL in AUD (13). QoL differs from HRQoL since it investigates the overall quality of life irrespectively of any health condition, whereas HRQoL necessarily refers to the impact of a particular health status. Nevertheless, the two terms are often used interchangeably in the literature, leading sometimes to confusion (14).

As HRQoL is considered as a relevant measure of treatment outcome, several studies have been conducted in various conditions to identify its predictors. These studies reported that cognitive impairments, sleep disturbances, mood disorders, impulsivity and demographic variables such as age, education, and gender were significantly related to HRQoL in multiple sclerosis, cancer and chronic diseases in elderly people (15) (16) (17) (18). In AUD, general QoL seems to be associated with gender, age (19) (20), depression (11), and severity of AUD (19). But to date, no study has examined the specific determinants of HRQoL in AUD.

Some studies revealed that HRQoL is altered in AUD patients (11). However, despite the fact that HRQoL is considered crucial in the management of AUD, it remains little explored and only with generic scales, not specific to AUD (21). Because these scales were designed by clinicians or researchers, they did not include opinions and perceptions of patients, contrary to the recommendations of the Food and Drug Administration (22) that encourages to use patient-reported outcome (PRO) measures.

The only specific HRQoL assessments in AUD was the AIQoL-9 (23). However, this scale was derived from a generic scale, called the SF-36, by eliminating non relevant items. In this respect, this tool did not meet the criteria for PRO instruments, which are defined as reports that came directly from the patient without amendment or interpretation of the patient's response by a clinician or anyone else (22). To remedy this, Luquiens et al. (13) (24) have developed and validated a tool, called "Alcohol Quality of Life Scale" (AQoLS), designed from the patients' perspective. The present study aims at describing HRQoL in recently detoxified patients with severe AUD (SAUD) using this validated tool, as well as at exploring the relationships between this questionnaire and socio-demographic, cognitive and clinical variables to identify the most significant determinants of HRQoL in SAUD patients.

\section{li - Materials And Methods}

\section{Participants}

We conducted a cross-sectional study enrolling 53 recently detoxified SAUD inpatients and 38 healthy controls $(\mathrm{HC})$. None of them had a history of neurological, endocrinal, or infectious diseases, neither depression assessed using both the Beck Depression Inventory (BDI) (25) and a psychiatric assessment, nor other forms of substance use disorder (except tobacco). All participants were informed about the study approved by the local ethics committee of Caen University Hospital (CPP Nord Ouest III, no. IDRCB: 2011-A00495-36) before their inclusion and signed a written informed consent form.

SAUD patients were recruited by clinicians while they were receiving withdrawal treatment as inpatients at Caen University Hospital. Although recently detoxified, patients no longer showed signs of withdrawal at inclusion as 
assessed by the Cushman's scale (26). sAUD patients met "alcohol dependence" criteria according to the DSMIV-TR (27) or "severe AUD" criteria according to the DSM-5 (28) for at least five years.

sAUD patients and HC subjects were matched for age, gender and education $(p=0.33, p=0.21$ and $p=0.12$ respectively). Patients tended to live more frequently alone than $\mathrm{HC}(\mathrm{p}=0.05)$ (Table 1).

Table 1. Socio-demographic, cognitive and clinical features of the severe Alcohol Use Disorder (SAUD) patients and Healthy Controls $(\mathrm{HC})$. 


\begin{tabular}{|c|c|c|c|}
\hline & $\begin{array}{l}\text { sAUD patients } \\
(\mathrm{n}=33)\end{array}$ & $\begin{array}{l}\text { HC subjects } \\
(n=38)\end{array}$ & $\begin{array}{l}\text { Between- } \\
\text { group }\end{array}$ \\
\hline & $(M \pm S D)$ & $(M \pm S D)$ & comparisons \\
\hline \multicolumn{4}{|l|}{ SOCIO-DEMOGRAPHIC } \\
\hline Age (years) & $46.15 \pm 10.13$ & $44.34 \pm 6.07$ & $p=0.33$ \\
\hline Gender, men (\%) & $86.79 \%$ & $94.73 \%$ & $p=0.21$ \\
\hline Education (years) & $11.32 \pm 2.09$ & $11.82 \pm 0.73$ & $p=0.12$ \\
\hline Family status, living alone (\%) & $54.72 \%$ & $34.21 \%$ & $p=0.05$ \\
\hline \multicolumn{4}{|l|}{ COGNITIVE } \\
\hline Episodic memory (z-score) & $-1.55 \pm 1.22$ & $0 \pm 1$ & $H C>S A U D^{*}$ \\
\hline Working memory (z-score) & $-1.27 \pm 0.82$ & $0 \pm 1$ & $H C>s A U D^{*}$ \\
\hline Executive functions (z-score) & $-1.08 \pm 1.49$ & $0 \pm 1$ & $\mathrm{HC}>\mathrm{sAUD}^{*}$ \\
\hline Processing speed (z-score) & $-1.57 \pm 1.65$ & $0 \pm 1$ & $H C>s_{A U D}^{*}$ \\
\hline \multicolumn{4}{|l|}{ CLINICAL } \\
\hline \multicolumn{4}{|l|}{ Sleep } \\
\hline PSQI & $\begin{array}{l}8.74 \pm 3.27 \\
(2 \mathrm{MD})\end{array}$ & $2.37 \pm 1.51$ & $H C<$ sAUD $^{*}$ \\
\hline \multicolumn{4}{|l|}{ Depression and anxiety } \\
\hline BDI & $\begin{array}{l}17.30 \pm 10.91 \\
(1 \mathrm{MD})\end{array}$ & $2.89 \pm 3.09$ & $H C<$ sAUD $^{*}$ \\
\hline STAI B (trait anxiety) & $51.21 \pm 10.62$ & $32.16 \pm 6.87$ & $\mathrm{HC}<\mathrm{SAUD}^{*}$ \\
\hline \multicolumn{4}{|l|}{ Impulsivity } \\
\hline S-UPPS-P & $48.45 \pm 10.99$ & $\begin{array}{l}33.24 \pm \\
11.15\end{array}$ & $H C<$ sAUD $^{*}$ \\
\hline Negative Urgency & $10.38 \pm 3.41$ & $7.13 \pm 3.23$ & $\mathrm{HC}<\mathrm{SAUD}^{*}$ \\
\hline Lack of Premeditation & $8.98 \pm 2.54$ & $6.24 \pm 2.11$ & $H C<$ SAUD $^{*}$ \\
\hline Lack of perseverance & $8.32 \pm 2.92$ & $5.68 \pm 1.95$ & $\mathrm{HC}<\mathrm{SAUD}^{*}$ \\
\hline Sensation Seeking & $10.64 \pm 8.04$ & $6.79 \pm 2.36$ & $H C<$ SAUD $^{*}$ \\
\hline Positive Urgency & $11.43 \pm 2.94$ & $7.5 \pm 3.35$ & $H C<$ SAUD $^{*}$ \\
\hline \multicolumn{4}{|l|}{ Alcohol history } \\
\hline AUDIT & $28.58 \pm 5.75$ & $2.42 \pm 1.64$ & $\mathrm{HC}<\mathrm{sAUD}^{*}$ \\
\hline
\end{tabular}


Age of onset of AUD (years)

Daily alcohol consumption during the month preceding withdrawal (units ${ }^{a}$ )
$31.30 \pm 8.87$

$(3 \mathrm{MD})$

$19.30 \pm 7.01$

$(1 \mathrm{MD})$

AUD: Alcohol Use Disorder; n: sample size; M: mean; SD- standard deviation; HC: healthy controls; T: Tendency; BDI: Beck Depression Inventory; STAI: State-Trait Anxiety Inventory; AUDIT: Alcohol Use Disorders Identification Test; PSQI: Pittsburgh Sleep Quality Index; S-UPPS-P: Short form of negative Urgency, lack of Premeditation, lack of Perseverance, sensation Seeking, Positive urgency. MD: Missing Data; ${ }^{*}$ p<0.01; a: an alcohol unit = 10 $\mathrm{g}$ of pure alcohol.

$\mathrm{HC}$ subjects were interviewed with the Alcohol Use Disorder Identification Test (AUDIT) (29) to ensure that they did not meet the criteria for alcohol abuse (AUDIT $<7$ for men and $<6$ for women). None of the controls had a BDI score > 29 (25) nor sleep complaint (Pittsburgh Sleep Quality Index [PSQI] score $\leqslant 5$ ) (30).

\section{Experimental protocol}

\subsection{Assessment of Health-Related Quality of Life (HRQoL) in SAUD patients}

HRQoL was assessed using AQoLS, which is a self-assessment questionnaire including 34 items and measuring the specific impact of alcohol on HRQoL over the last 4 weeks. AQoLS has been specifically developed for AUD patients as all the items have been directly generated by patients and reflect, therefore, their concerns. AQoLS explores 7 domains: activities, relationships, living conditions, negative emotions, selfesteem, control and sleep. The number of items for each domain and some examples are presented in Table 2. For each item, the level of agreement is reported based on a 4-point Likert scale, ranging from 0 (not at all) to 3 (very much). Thus, a high total AQoLS score reflects poor HRQoL.

Table 2. AQoLS domains, number of items and examples.

\begin{tabular}{|c|c|c|}
\hline AQoLS domains & $\begin{array}{l}\text { Number of } \\
\text { items }\end{array}$ & Examples \\
\hline Activities & 10 & $\begin{array}{l}\text { I have felt I miss out on everyday activities with family and } \\
\text { friends }\end{array}$ \\
\hline Relationships & 6 & Alcohol has interfered with my relationships with friends \\
\hline Living conditions & 4 & Alcohol has had a negative effect on my housing situation \\
\hline $\begin{array}{l}\text { Negative } \\
\text { emotions }\end{array}$ & 2 & I have worried about alcohol causing problems in my life \\
\hline Self-esteem & 5 & I have neglected my general health \\
\hline Control & 5 & I have planned my days around alcohol \\
\hline Sleep & 2 & I have not been getting enough sleep \\
\hline
\end{tabular}

AQoLS: Alcohol Quality of Life Scale 


\subsection{Neuropsychological assessment}

Participants underwent a detailed neuropsychological examination targeting verbal episodic memory, working memory, executive functions, and processing speed.

\section{Episodic memory}

Verbal episodic memory was assessed using the French version of the Free and Cued Selective Reminding Test (FCSRT) (31). We used the sum of the three free recalls of learning trials.

\section{Working memory}

Verbal working memory was assessed with the digit span tasks (forward and backward) of WAIS III (32).

\section{Executive functions}

We evaluated mental flexibility using the number of perseverative errors on the Modified Card Sorting Tests (MCST) (33). Inhibition was measured using the time (in seconds) needed to complete the interference condition minus the time needed for the denomination condition of the Stroop Test (34).

\section{Processing speed}

Processing speed was assessed using the denomination condition of the Stroop Test (time in seconds) (34).

\subsection{Assessment of subjective sleep quality}

Subjective sleep quality was assessed using the PSQI, which is a 19-item questionnaire exploring sleep quality and sleep disturbances. Seven components are explored (subjective sleep quality, sleep latency, sleep duration, habitual sleep efficiency, sleep disturbances, use of sleep medications, and daytime dysfunction) and scored on a scale ranging from 0 to 3 . The PSQI total score corresponds to the sum of the scores obtained for each component, and ranges from 0 (no difficulty) to 21 (major sleep difficulties).

Of note, the original version of the PSQI questioning the previous month has been proposed to HC subjects and 11 sAUD patients. A modified version assessing sleep quality during the previous week (made with the authors' agreement) was administered to 20 sAUD patients (two patients had missing data). Since a comparison between the original and modified versions of the PSQI did not reveal any significant difference $(\mathrm{t}(49)=1.04$, $\mathrm{p}=0.30)$, PSQI data were pooled together.

\subsection{Assessment of mood}

Participants completed the BDI (25), a 21-item self-reported questionnaire that evaluates symptoms and overt behavioural manifestations of depression. Each item has four possible responses, ranging from 0 (e.g. "I do not feel sad") to 3 (e.g. "I am so sad or unhappy that I can't stand it"). The total score ranges from 0 to 63 with higher scores indicating higher levels of depression.

Participants also filled out the STAI B (35), a 20-item self-completed questionnaire that measures trait anxiety defined as the propensity to be generally anxious. Each item has four possible responses ranging from 1 
(almost never) to 4 (almost always): a higher score indicates greater trait anxiety.

\subsection{Assessment of impulsivity}

Participants completed the short version of the Urgency, Premeditation, Perseverance, Sensation Seeking, and Positive Urgency impulsivity behavioral scale (36), which is a 20-item self-reported questionnaire that measures personality facets associated with impulsivity. The S-UPPS-P includes five subscales (negative urgency. tendency to act rashly under extreme negative emotions, lack of premeditation: tendency to act without thinking, lack of perseverance: inability to remain focused on a task, sensation seeking: tendency to seek out novel and thrilling experiences, and positive urgency. tendency to act rashly under extreme positive emotions). Each item of the S-UPPS-P has four possible responses ranging from 1 (strongly agree) to 4 (strongly disagree) with higher scores indicating a higher level of impulsivity.

\subsection{Alcohol history}

Alcohol use was first explored using the AUDIT (29). The total score ranges from 0 to 40 with higher scores indicating greater hazardous drinking. We also collected the age of onset of AUD, and daily alcohol consumption during the month preceding alcohol withdrawal.

\section{Statistical analyses}

Cognitive data were converted into standardized z-scores using the mean and standard deviation of the HC. When necessary, the direction of the $z$-score was reversed (e.g number of errors) so that all the z-scores had the same direction: the higher the $z$-score, the better the performance. When a domain included several variables (e.g executive functions), a composite score was calculated by averaging the z-scores obtained for each variable.

We first used descriptive statistics to analyze HRQoL (AQoLS total score and scores for each domain) in SAUD patients. Since the domains of the AQoLS do not have the same number of items (see Table 2), we normalized the subscores, dividing, for each patient, the score of each domain by the maximum score that could be obtained for that domain. Thus, for each domain the score ranges from 0 to 1 . Then, in order to compare all the domains to each other, repeated measures analysis of variances (ANOVA) were conducted followed by Bonferroni post hoc tests.

Then, Student's $t$-tests were carried out to compare cognitive and clinical variables between sAUD patients and $\mathrm{HC}$.

In SAUD patients, the relationships between HRQoL and socio-demographic (age and education), cognitive and clinical variables were examined using Pearson's correlations. Student's $t$-tests were performed to examine a potential effect of gender and living conditions (alone $v s$ with a partner) on HRQoL. Variables that were significantly correlated with AQoLS were entered in a stepwise linear regression analysis to determine the best predictor(s) of HRQoL. Both, backward and forward models were used to ensure congruence.

An exploratory analysis was also performed to examine the relationships between the different AQoLS domains and socio-demographic, cognitive, and clinical variables. For this analysis, we notably used the 
scores on the subscales of the S-UPPS-P questionnaire.

Given the number of statistical analyses, the threshold of statistical significance was set at $p<0.01$ for all analyses. Statistical analyses were carried out using JASP (version 0.13.1).

\section{lii - Results}

HRQoL in SAUD patients

The mean AQoLS score ( \pm standard deviation) was $49.94 \pm 18.25$ with a great variability between patients (total score ranging from 18 to 92). The scores obtained for each AQoLS domain as well as the total score are presented in Table 3.

Table 3. Results on the AQoLS questionnaire in SAUD patients (raw data).

\begin{tabular}{|lllllllll|}
\hline & Activities & Relationships & $\begin{array}{l}\text { Living } \\
\text { conditions }\end{array}$ & $\begin{array}{l}\text { Negative } \\
\text { emotions }\end{array}$ & $\begin{array}{l}\text { Self- } \\
\text { esteem }\end{array}$ & Control & Sleep & $\begin{array}{l}\text { AQoLS } \\
\text { Total } \\
\text { score }\end{array}$ \\
\hline Mean & 12.19 & 10.62 & 4.45 & 3.70 & 6.70 & 7.06 & 2.23 & 49.94 \\
\hline $\begin{array}{l}\text { Standard } \\
\text { Deviation }\end{array}$ & 5.87 & 3.74 & 2.65 & 1.61 & 3.57 & 3.84 & 2.04 & 18.25 \\
\hline Range & $3-26$ & $3-18$ & $1-10$ & $0-6$ & $0-15$ & $1-15$ & $0-6$ & $18-92$ \\
\hline $\begin{array}{l}\text { Maximum } \\
\text { possible } \\
\text { score }\end{array}$ & 30 & 18 & 12 & 6 & 15 & 15 & 6 & 102 \\
\hline
\end{tabular}

AQoLS: Alcohol Quality of Life Scale, sAUD: severe Alcohol Use Disorder.

As presented in Figure 1, we identified significant statistical differences between a set of AQoLS domains. Indeed, after normalization, the four main domains for which sAUD patients complained the most (namely "negative emotions", "control", "relationships" and "sleep") (Table 4) were all significantly different from the following domains "activities", "living conditions", and "self-esteem" for which patients complained the least. In addition, the score for the "sleep" domain was significantly higher compared to those obtained in the "activities" and "living conditions" domains (see Figure 1).

Table 4. Results on the AQoLS questionnaire in SAUD patients (normalized data).

\begin{tabular}{|llllllll|}
\hline & Activities & Relationships & $\begin{array}{l}\text { Living } \\
\text { conditions }\end{array}$ & $\begin{array}{l}\text { Negative } \\
\text { emotions }\end{array}$ & $\begin{array}{l}\text { Self- } \\
\text { esteem }\end{array}$ & Control & Sleep \\
\hline Mean & 0.41 & 0.58 & 0.37 & 0.62 & 0.45 & 0.60 & 0.54 \\
\hline $\begin{array}{l}\text { Standard } \\
\text { Deviation }\end{array}$ & 0.20 & 0.20 & 0.22 & 0.27 & 0.24 & 0.26 & 0.34 \\
\hline Range & $0.10-$ & $0.17-1$ & $0.08-0.83$ & $0-1$ & $0-1$ & $0.07-$ & $0-1$ \\
\hline
\end{tabular}


AQoLS: Alcohol Quality of Life Scale, sAUD: severe Alcohol Use Disorder.

\section{Comparison of neuropsychological performance, sleep, mood and impulsivity between HC and sAUD patients}

SAUD patients presented lower performance than $\mathrm{HC}$ for all the cognitive functions assessed (episodic memory: $\mathrm{t}(89)=-6.43$, p<0.001; working memory: $\mathrm{t}(89)=-7.96, \mathrm{p}<0.001$; executive functions: $\mathrm{t}(89)=-4.11$, $\mathrm{p}<0.001$ and processing speed: $t(89)=-5.21, p<0.001 ;$ Table 1$)$.

The PSQI score was higher in SAUD patients than in $\mathrm{HC}(\mathrm{t}(87)=11.14, \mathrm{p}<0.001$; Table 1$)$, reflecting more severe sleep disturbances.

Compared to HC, sAUD patients exhibited higher BDI and STAI B scores $(\mathrm{t}(88)=7.91, \mathrm{p}<0.001$ and $\mathrm{t}(89)=$ $9.69, \mathrm{p}<0.001$ respectively; Table 1 ), indicating that sAUD patients had more depressive symptoms and were more anxious than HC.

A significant difference was observed between the two groups on the S-UPPS-P. Compared to HC, sAUD patients showed higher scores on the S-UPPS-P total score $(t(89)=6.47, p<0.001)$, reflecting greater impulsivity. More precisely, SAUD patients showed higher scores than HC on all the five subscales of the SUPPS-P: negative urgency ( $t(89)=4.63, p<0.001$ ), lack of premeditation ( $(89)=5.45, p<0.001)$, lack of perseverance $(t(89)=4.84, p<0.001$, sensation seeking $(t(89)=2.85, p=0.005)$, and positive urgency $(t(89)=$ 5.93, $p<0.001)$.

\section{Determinants of HRQoL in SAUD patients}

No significant correlation was found between the AQoLS total score and the demographic variables in SAUD patients (age: $r=-0.21$; education: $r=0.09$, all $p$ values $>0.13$ ).

Student $t$-tests did not reveal any significant effect of gender $(t(51)=0.82, p=0.41)$ or living conditions $(t(51)=$ $-0.19, p=0.85)$ on the AQoLS total score.

The AQoLS total score did not correlate with cognitive performance either (episodic memory: $r=0.03$; working memory: $r=-0.07$; executive functions: $r=0.25$; processing speed: $r=0.22$; all $p$ values $>0.06$ ).

None of the variables reflecting sleep disturbances (PSQI: $r=0.22, p=0.12$ ) or alcohol history (AUDIT: $r=0.27$, $p=0.05$; age of onset of AUD: $r=-0.23, p=0.11$; daily alcohol consumption: $r=0.17, p=0.22$ ) were significantly related to the AQoLS total score.

The BDI as well as the STAI B scores show a significant positive correlation with the AQoLS total score ( $r=0.54$, $r=0.58$ respectively; $p<0.001$, Figure $2 A$ and $B$ ). Thus, the more depressed and anxious sAUD patients were, the poorer was their HRQoL. The S-UPPS-P total score $(r=0.60, p<0.001)$ positively correlated with the AQoLS total score (Figure 2C). Thus, the more sAUD patients exhibited impulsive behaviours, the poorer was their HRQoL.

A stepwise multiple linear regression analysis was then conducted using the AQoLS total score as the dependent variable and the BDI, STAI-B and S-UPPS-S total scores as predictors based on the results of the correlation analyses. Since the backward and the forward models provided the same results, we present only the forward model. The first step showed that the S-UPPS-P score explained $35.8 \%$ of the variance of the 
AQoLS total score. In a second (and final) step, the model showed that the S-UPPS-P and the STAI B scores were the only significant predictors of the AQoLS total score, explaining $47.7 \%$ of the variance (Table 5).

Table 5. Results of forward stepwise regressions models showing the variables most strongly associated with HRQoL in sAUD patients.

\begin{tabular}{|lllll|}
\hline Factor & Unstandardized coefficient $(95 \% \mathrm{Cl})$ & $\boldsymbol{\beta}^{*}$ & $\mathbf{R}^{2}$ & $\boldsymbol{p}$ value \\
\hline Step 1 & & & & \\
\hline Intercept & $2.17(-16.56-20.90)$ & NA & NA & 0.82 \\
\hline S-UPPS-P score & $0.99(0.61-1.37)$ & 0.60 & 0.358 & $<0.001$ \\
\hline Step 2 & & & & \\
\hline Intercept & $-17.21(-37.89-3.47)$ & NA & NA & 0.10 \\
\hline S-UPPS-P score & $0.67(0.28-1.07)$ & 0.406 & NA & 0.001 \\
\hline STAI B score & $0.68(0.27-1.09)$ & 0.395 & 0.445 & 0.002 \\
\hline Full model & NA & NA & 0.477 & $<0.001$ \\
\hline
\end{tabular}

Cl: Confidence Interval, $\beta^{*}$ : Standardized beta coefficients, $\mathrm{R}^{2}$ : R-Squared, NA: Not Applicable.

S-UPPS-P: Short form of- negative Urgency, lack of Premeditation, lack of Perseverance, sensation Seeking, Positive urgency; STAI B: State-Trait Anxiety Inventory part B.

\section{Exploratory analysis}

Using the scores of the different AQoLS domains, we found that the scores for the "control" $(r=0.47, r=0.62)$, "activities" ( $r=0.55 ; r=0.59)$, "self-esteem" ( $r=0.56 ; r=0.56)$, "sleep" ( $r=0.47 ; r=0.53$ ) domains significantly correlated with the STAI B and the S-UPPS-P scores (all p values $<0.001$ ). This indicates that the more the sAUD patients exhibited impulsive behaviors, the more they perceived their control, activities, self-esteem, sleep as being impacted by alcohol consumption. Moreover, we found that the scores on "living conditions" and "negative emotions" domains significantly correlated with the STAI B and the S-UPPS scores ( $r=0.39 ; r=0.40$ respectively, all $p$ values $<0.004)$. Thus, the more sAUD patients were anxious, the poorer were their living conditions. Furthermore, the more patients exhibited impulsive behaviors, the more they expressed negative emotions.

When considering the scores on the different subscales of the S-UPPS-P, we found significant relationships between positive urgency and the "activities" ( $r=0.45, p<0.001)$, "negative emotions" ( $r=0.36, p=0.008)$, "selfesteem" ( $r=0.43, p<0.001)$, "control" ( $r=0.58, p<0.001)$ and "sleep" domains $(r=0.11, p<0.001)$. The lack of premeditation significantly correlated with the "activities', "self-esteem", "control" and "sleep" domains ( $r=0.58$; $r=0.46 ; r=0.52 ; r=0.46$ respectively, all $p$ values $<0.001)$. Significant relationships were also found between the lack of perseverance and the "activities" ( $r=0.39, p=0.004)$ and "control" domains $(r=0.37, p=0.006)$. Finally, negative urgency significantly correlated with the "self-esteem" ( $r=0.37, p=0.006)$, "control" $(r=0.48, p<0.001)$ and "sleep" domains ( $r=0.37, p=0.007)$. 


\section{IV - Discussion}

Our study aimed at describing HRQoL in recently detoxified SAUD patients using a tool specifically designed for this clinical population. We also investigated the relationships between HRQoL and socio-demographic, cognitive and clinical variables to identify those that best predicted HRQoL.

The pattern of cognitive deficits, sleep disturbances, mood alterations and impulsivity observed in the AUD patients included in this study is in accordance with the literature. Indeed, cognitive impairments have repeatedly been found in recently detoxified AUD patients (37), with deficits of verbal episodic memory, executive functions, processing speed and working memory (38) (39) (40). Sleep disturbances are also frequently reported by patients (41). Moreover, AUD is often associated with mood disorders (42). Finally, sAUD patients exhibited more traits of impulsivity than controls, in line with several reports (43).

It is well known that AUD patients suffer from a poor QoL/HRQoL (11) for a review). In the present study, we used a tool specifically designed for this clinical population and found that recently detoxified sAUD patients were able to report the harmful effects their severe and chronic alcohol consumption had on different domains of HRQoL. Previous studies have shown that some demographic features of AUD patients are significantly associated with QoL. Thus, increasing age (20), being a woman (44) (20) (23) (45), having a low education level (45) and living alone (46) have a negative impact on QoL. However, in agreement with other studies that did not show any association between demographic variables and QoL (see for example (47) ), we did not find such relationships in our sample of sAUD patients when considering HRQoL specifically.

Our analyses did not reveal any significant relationship between cognitive abilities and HRQoL either. This result stands at odds with other studies showing a link between cognitive functioning and QoL/HRQoL in various conditions such as Alzheimer's disease and Mild Cognitive Impairment (48), multiple sclerosis, stroke, and Huntington's disease (49). Our findings suggest that the cognitive tasks we used are either not sensitive enough to reveal strong associations with HRQoL or do not target the relevant cognitive abilities. As emotion decoding and social cognition are known to be impaired in AUD patients (50) and to affect interpersonal relationships (51), further studies assessing these functions are needed to unravel the determinants of HRQoL. Another explanation of this absence of relationship between cognitive abilities and HRQoL could be that AQoLS is a self-reported questionnaire potentially affected by cognitive deficits or self-awareness impairments (39). It would thus be difficult to find associations between objective cognitive measures and subjective selfevaluation. However, as previously mentioned, such relationships have been found in other clinical populations with cognitive impairments and we did not systematically find significant relationships between subjective measures. Indeed, contrary to our expectations, we did not observe any association between subjective sleep quality and self-assessment of HRQoL in the present study. Nevertheless, the deleterious effect of sleep disturbances on general QoL has been revealed in dementia (52), epilepsy and multiple sclerosis (53) (54), and psychiatric disorders (55). In AUD, a few studies reported that poor sleep quality is related to poor QoL (42) or is an important component of HRQoL (56). The absence of relationship between sleep quality and HRQoL in our study could be explained by the fact that recently detoxified SAUD patients with executive deficits could not be cognitively able to accurately self-evaluate their sleep (57). Further investigations using objective sleep measures are required to better understand the relationship between sleep and HRQOL in AUD. 
Several studies have addressed the relationships between mood and QoL/HRQoL in AUD (58). Both depression and anxiety may account for impaired QoL in AUD patients (23) (59). In agreement with these studies, we found a significant association between mood variables (depression/ anxiety) and HRQoL. Thus, the more sAUD patients express symptoms of depression and anxiety, the lower was their HRQoL.

In contrast with previous studies conducted in AUD and binge drinking, we did not find any significant correlation between HRQOL and the AUDIT score, the daily alcohol consumption during the month preceding withdrawal, or the age of onset of AUD (60) (61). This absence of relationship suggests either that the severity of AUD is not related to HRQoL or that quantitative measures of alcohol history used in the present study are not good indicators. Craving intensity or psychological dependence may be better determinants of HRQoL and should be further investigated.

We identified impulsivity and anxiety, among the studied variables, as the best determinants of HRQoL in AUD: the more sAUD patients were anxious and impulsive, the poorer was their HRQoL. The exploratory analysis showed that "control", "activities", "self-esteem" and "sleep" domains were especially impacted by anxiety and impulsivity. We also showed that the "living conditions" domain was impacted by anxiety, as well as the "negative emotions" domain was impacted by impulsivity.

The fact that anxiety and impulsivity were the only significant determinants of HRQoL in AUD is clinically highly relevant. Several studies have found that anxiety is a significant determinant for QoL in AUD (see for example (62)). Indeed, anxiety may have a bidirectional relationship with AUD. Indeed, some people with anxiety disorders tend to use alcohol as a self-medication to help coping with their symptoms, which in turn favor the development of AUD (63) (64). Conversely, other studies have shown that AUD also induces anxiety symptoms (65) (66) (67). Anxiety appears therefore as a critical factor to consider in the treatment of AUD patients.

Impulsivity has been found to impair QoL in patients with compulsive behaviors (68) or bipolar disorder (69). Impulsivity results in serious physical, social and psychological issues, which would lead in cascade to functional impairments. In bipolar patients, it was found that impulsivity influences QoL both indirectly through altered level of functioning and more directly as suggested by the relationship between impulsivity and QoL that remains significant after controlling for the level of functioning (70). The fact that impulsivity was an important determinant of HRQoL in AUD is clinically highly relevant. Indeed, several studies indicated that impulsivity may not only precede the development of AUD (71) but also favors relapse (72) even after sustained abstinence (73).

In AUD, taking account of anxiety and impulsivity is thus crucial since they contribute, notably in an indirect way through alteration of HRQoL, to the treatment outcome. In this respect, in addition to pharmacological treatments, several interventions such as physical activity (74) or meditation (75) could be proposed to manage anxiety and impulsivity in AUD.

\section{V - Conclusion}

To conclude, our study is the first to assess HRQoL in a group of carefully selected recently detoxified SAUD patients using a questionnaire especially designed for this clinical population, combined with a 
neuropsychological examination, assessments of subjective sleep quality, mood, impulsivity, and alcohol history indicators. Our findings reveal that in SAUD patients, anxiety and impulsivity are crucial determinants of HRQoL. Thus, anxiety and impulsivity should be more systematically investigated and targeted by nonpharmacological interventions in order to improve treatment outcomes.

\section{Declarations}

\section{Ethics approval and consent to participate}

All participants were informed about the study approved by the local ethics committee of Caen University Hospital (CPP Nord Ouest III, no. IDRCB: 2011-A00495-36) before their inclusion and signed a written informed consent form.

\section{Consent for publication}

Not applicable

\section{Availability of data and materials}

The datasets used and/or analysed during the current study are available from the corresponding author on reasonable request.

\section{Competing interests}

The authors declare that they have no competing interests

\section{Funding}

This work was supported by the French National Institute for Health and Medical Research (INSERM), the French National Agency for Research (ANR), and the Conseil Regional de Normandie.

\section{Authors' contributions}

NL: formal analysis, writing-original draft, Visualization.

AL: investigation, writing-review \& editing.

SS: investigation, writing-review \& editing.

NC: investigation, resources, writing-review \& editing, project administration.

CB: investigation, resources, writing-review \& editing.

FV: investigation, resources, writing-review \& editing.

GR: conceptualization, methodology, writing-review \& editing, supervision, funding acquisition.

ALP: conceptualization, methodology, writing-review \& editing, supervision, funding acquisition 
The authors are grateful to Coralie Lannuzel and Hélène Beaunieux for their contribution at various stages of the study. We would also like to thank all the participants.

\section{References}

1. Carvalho AF, Heilig M, Perez A, Probst C, Rehm J. Alcohol use disorders. Lancet. 31 2019;394(10200):781-92.

2. World Health Organization, Management of Substance Abuse Team, World Health Organization. Global status report on alcohol and health 2018. [Internet]. 2018 [cité 8 avr 2020]. Disponible sur: http://www.who.int/substance_abuse/publications/global_alcohol_report/en/

3. Mann K, Aubin H-J, Witkiewitz K. Reduced Drinking in Alcohol Dependence Treatment, What Is the Evidence? Eur Addict Res. 2017;23(5):219-30.

4. Mojtabai R, Crum RM. Perceived unmet need for alcohol and drug use treatments and future use of services: results from a longitudinal study. Drug Alcohol Depend. 1 janv 2013;127(1-3):59-64.

5. Brousse G, Bendimerad P, de Chazeron I, Llorca PM, Perney P, Dematteis M. Alcoholism Risk Reduction in France: A Modernised Approach Related to Alcohol Misuse Disorders. Int J Environ Res Public Health. nov 2014;11(11):11664-75.

6. Witkiewitz K. Predictors of Heavy Drinking During and Following Treatment. Psychol Addict Behav. sept 2011;25(3):426-38.

7. Finney JW, Moos RH, Timko C. The course of treated and untreated substance use disorders: Remission and resolution, relapse and mortality. In: Addictions: A comprehensive guidebook. New York, NY, US: Oxford University Press; 1999. p. 30-49.

8. Luquiens $\mathrm{A}$, Reynaud M, Aubin HJ. Is controlled drinking an acceptable goal in the treatment of alcohol dependence? A survey of French alcohol specialists. Alcohol Alcohol. oct 2011;46(5):586-91.

9. Ugochukwu C, Bagot KS, Delaloye S, Pi S, Vien L, Garvey T, et al. The importance of quality of life in patients with alcohol abuse and dependence. Harv Rev Psychiatry. févr 2013;21(1):1-17.

10. The World Health Organization Quality of Life assessment (WHOQOL): position paper from the World Health Organization. Soc Sci Med. nov 1995;41(10):1403-9.

11. Levola J, Aalto M, Holopainen A, Cieza A, Pitkänen T. Health-related quality of life in alcohol dependence: a systematic literature review with a specific focus on the role of depression and other psychopathology. Nord J Psychiatry. août 2014;68(6):369-84.

12. European Medicines Agency. Reflection Paper on the Regulatory Guidance for the Use of Health Related Quality of Life (HRQL) Measures in the Evaluation of Medicinal Products. European Medicines Agency, London; 2005.

13. Luquiens A, Whalley D, Crawford SR, Laramée P, Doward L, Price M, et al. Development of the Alcohol Quality of Life Scale (AQoLS): a new patient-reported outcome measure to assess health-related quality of life in alcohol use disorder. Qual Life Res. juin 2015;24(6):1471-81. 
14. Karimi M, Brazier J. Health, Health-Related Quality of Life, and Quality of Life: What is the Difference? Pharmacoeconomics. 2016;34(7):645-9.

15. Lamargue Hamel D, Deloire M, Ruet A, Charré-Morin J, Saubusse A, Ouallet J-C, Brochet B. Deciphering Depressive Mood in Relapsing-Remitting and Progressive Multiple Sclerosis and Its Consequence on Quality of Life. PLoS One. 2015;10. https://doi.org/10.1371/journal.pone.0142152

16. Quinten C, Coens C, Ghislain I, Zikos E, Sprangers M-A-G, Ringash J, Martinelli F, Ediebah D-E, Maringwa J, Reeve B-B, Greimel E, King M-T, Bjordal K, Flechtner H-H, Schmucker-Von Koch J, Taphoorn M-J-B, Weis J, Wildiers H, Velikova G, Bottomley A, PROBE, EORTC Clinical Groups. The effects of age on health-related quality of life in cancer populations: A pooled analysis of randomized controlled trials using the European Organisation for Research and Treatment of Cancer (EORTC) QLQ-C30 involving 6024 cancer patients. Eur J Cancer 51. 2015: 2808-2819. https://doi.org/10.1016/j.ejca.2015.08.027

17. Ruet A, Deloire M, Hamel D, Ouallet J-C, Petry K, Brochet B. Cognitive impairment, health-related quality of life and vocational status at early stages of multiple sclerosis: a 7-year longitudinal study. J Neurol. 2013; 260: 776-784. https://doi.org/10.1007/s00415-012-6705-1

18. Scaravilli T, Gasparoli E, Rinaldi F, Polesello G, Bracco F. Health-related quality of life and sleep disorders in Parkinson's disease. Neurol Sci. 2003; 24: 209-210. https://doi.org/10.1007/s10072-003-0134-y

19. Daeppen J-B, Faouzi M, Sanchez N, Rahhali N, Bineau S, Bertholet N. Quality of Life Depends on the Drinking Pattern in Alcohol-Dependent Patients. Alcohol and Alcoholism. 1 juill 2014;49(4):457-65.

20. Lahmek P, Berlin I, Michel L, Berghout C, Meunier N, Aubin H-J. Determinants of improvement in quality of life of alcohol-dependent patients during an inpatient withdrawal programme. Int J Med Sci. 18 mai 2009;6(4):160-7.

21. Luquiens A, Reynaud M, Falissard B, Aubin HJ. Quality of life among alcohol-dependent patients: how satisfactory are the available instruments? A systematic review. Drug Alcohol Depend. 1 oct 2012;125(3):192-202.

22. Food and Drug Administration. Guidance for industry: patient-reported outcome measures: use in medical product development to support labeling claims. 2009.

23. Malet L, Llorca P-M, Beringuier B, Lehert P, Falissard B. AIQoL 9 for measuring quality of life in alcohol dependence. Alcohol Alcohol. avr 2006;41(2):181-7.

24. Luquiens A, Whalley D, Laramée P, Falissard B, Kostogianni N, Rehm J, Manthey J, Paille F, Aubin HJ. Validation of a new patient-reported outcome instrument of health-related quality of life specific to patients with alcohol use disorder: the Alcohol Quality of Life Scale (AQoLS). Qual Life Res. Jun 2016;25(6):1549-60.

25. Beck AT, Ward CH, Mendelson M, Mock J, Erbaugh J. An inventory for measuring depression. Archives of General Psychiatry. 1961;4(6):561-71.

26. Cushman P, Forbes R, Lerner W, Stewart M. Alcohol withdrawal syndromes: clinical management with lofexidine. Alcohol Clin Exp Res. avr 1985;9(2):103-8.

27. American Psychiatric Association. Diagnostic and Statistical manual of Mental Disorders. Third Edition. American Psychiatric Association; 2000.

28. American Psychiatric Association. Diagnostic and Statistical Manual of Mental Disorders. Fifth Edition. American Psychiatric Association; 2013. 
29. Gache P, Michaud P, Landry U, Accietto C, Arfaoui S, Wenger O, et al. The Alcohol Use Disorders Identification Test (AUDIT) as a screening tool for excessive drinking in primary care: reliability and validity of a French version. Alcohol Clin Exp Res. nov 2005;29(11):2001-7.

30. Buysse DJ, Reynolds CF, Monk TH, Berman SR, Kupfer DJ. The Pittsburgh Sleep Quality Index: a new instrument for psychiatric practice and research. Psychiatry Res. mai 1989;28(2):193-213.

31. Van der Linden M, Coyette F, Poitrenaud J, Kalafat M, Calicis F, Wyns C, et al. L'épreuve de rappel libre / rappel indicé à 16 items (RL/RI-16) [Internet]. Solal; 2004 [cité 14 déc 2020]. Disponible sur: https://orbi.uliege.be/handle/2268/26018

32. Wechsler D. Wechsler Memory Scale. Third Edition. Ed. Psychological Corporation, San Antonio, TX; 1997.

33. Cianchetti C, Corona S, Foscoliano M, Scalas F, Sannio-Fancello G. Modified Wisconsin Card Sorting Test: proposal of a supplementary scoring method. Archives of Clinical Neuropsychology. 1 juin 2005;20(4):555-8.

34. Stroop JR. Studies of interference in serial verbal reactions. Journal of Experimental Psychology. 1935;18(6):643-62.

35. Spielberger C-D, Gorsuch R-L, Lushene R, Vagg P-R, Jacobs G-A. Manual for the State-Trait Anxiety Inventory. Palo Alto, CA: Consulting Psychologists Press; 1983.

36. Billieux J, Rochat L, Ceschi G, Carré A, Offerlin-Meyer I, Defeldre A-C, et al. Validation of a short French version of the UPPS-P Impulsive Behavior Scale. Compr Psychiatry. juill 2012;53(5):609-15.

37. Le Berre A-P, Laniepce A, Segobin S, Pitel A-L, Sullivan E-V. Alcohol Use Disorder. The Oxford Handbook of Adult Cognitive Disorders. 2019.

38. Ihara $\mathrm{H}$, Berrios GE, London M. Group and case study of the dysexecutive syndrome in alcoholism without amnesia. J Neurol Neurosurg Psychiatry. juin 2000;68(6):731-7.

39. Le Berre A-P, Pinon K, Vabret F, Pitel A-L, Allain P, Eustache F, et al. Study of metamemory in patients with chronic alcoholism using a feeling-of-knowing episodic memory task. Alcohol Clin Exp Res. nov 2010;34(11):1888-98.

40. Pitel AL, Beaunieux H, Witkowski T, Vabret F, Guillery-Girard B, Quinette $P$, et al. Genuine episodic memory deficits and executive dysfunctions in alcoholic subjects early in abstinence. Alcohol Clin Exp Res. juill 2007;31(7):1169-78.

41. Laniepce A, Lahbairi N, Cabé N, Pitel AL, Rauchs G. Contribution of sleep disturbances to the heterogeneity of cognitive and brain alterations in alcohol use disorder. Sleep Med Rev. aug 2021; 58:101435.

42. Cohn TJ, Foster JH, Peters TJ. Sequential studies of sleep disturbance and quality of life in abstaining alcoholics. Addict Biol. déc 2003;8(4):455-62.

43. Lejuez CW, Magidson JF, Mitchell SH, Sinha R, Stevens MC, de Wit H. Behavioral and biological indicators of impulsivity in the development of alcohol use, problems, and disorders. Alcohol Clin Exp Res. aug 2010;34(8):1334-45.

44. Foster JH, Peters TJ, Marshall EJ. Quality of life measures and outcome in alcohol-dependent men and women. Alcohol. août 2000;22(1):45-52.

45. Morgan MY, Landron F, Lehert P, New European Alcoholism Treatment Study Group. Improvement in quality of life after treatment for alcohol dependence with acamprosate and psychosocial support. 
Alcohol Clin Exp Res. janv 2004;28(1):64-77.

46. Nogueira JM, Rodríguez-Míguez E. Using the SF-6D to measure the impact of alcohol dependence on health-related quality of life. Eur J Health Econ. may $2015 ; 16(4): 347-56$.

47. Manning V, Gomez B, Guo S, Low YD, Koh PK, Wong KE. An Exploration of Quality of Life and its Predictors in Patients with Addictive Disorders: Gambling, Alcohol and Drugs. International Journal of Mental Health and Addiction. août 2012;10(4):551-62.

48. Stites SD, Harkins K, Rubright JD, Karlawish J. Relationships between Cognitive Complaints and Quality of Life in Older Adults with Mild Cognitive Impairment, Mild Alzheimer's Disease Dementia, and Normal Cognition. Alzheimer Dis Assoc Disord. 2018;32(4):276-83.

49. Mitchell AJ, Kemp S, Benito-León J, Reuber M. The influence of cognitive impairment on health-related quality of life in neurological disease. Acta Neuropsychiatrica. 2010;22(1):2-13.

50. Le Berre A-P. Emotional processing and social cognition in alcohol use disorder. Neuropsychology. sept 2019;33(6):808-21.

51. Maurage P, Grynberg D, Noël X, Joassin F, Philippot P, Hanak C, et al. Dissociation between affective and cognitive empathy in alcoholism: a specific deficit for the emotional dimension. Alcohol Clin Exp Res. sept 2011;35(9):1662-8.

52. Petrovsky DV, McPhillips MV, Li J, Brody A, Caffeé L, Hodgson NA. Sleep disruption and quality of life in persons with dementia: A state-of-the-art review. Geriatr Nurs. 2018;39(6):640-5.

53. Piperidou C, Karlovasitou A, Triantafyllou N, Terzoudi A, Constantinidis T, Vadikolias K, et al. Influence of sleep disturbance on quality of life of patients with epilepsy. Seizure. oct 2008;17(7):588-94.

54. Tabrizi FM, Radfar M. Fatigue, Sleep Quality, and Disability in Relation to Quality of Life in Multiple Sclerosis. Int J MS Care. déc 2015;17(6):268-74.

55. McCall WV, Reboussin BA, Cohen W. Subjective measurement of insomnia and quality of life in depressed inpatients. J Sleep Res. mars 2000;9(1):43-8.

56. Foster JH, Peters TJ, Kind P. Quality of life, sleep, mood and alcohol consumption: a complex interaction. Addict Biol. janv 2002;7(1):55-65.

57. Laniepce A, Segobin S, Lannuzel C, Boudehent C, Ritz L, Urso L, et al. Neuropsychological and Neuroimaging Examinations of Self-Reported Sleep Quality in Alcohol Use Disorder With and Without Korsakoff's Syndrome. Alcohol Clin Exp Res. 2019;43(5):952-64.

58. Anker JJ, Kushner MG. Co-Occurring Alcohol Use Disorder and Anxiety: Bridging Psychiatric, Psychological, and Neurobiological Perspectives. Alcohol Res. 2019;40(1).

59. Saatcioglu O, Yapici A, Cakmak D. Quality of life, depression and anxiety in alcohol dependence. Drug Alcohol Rev. jan $2008 ; 27(1): 83-90$.

60. Fischer JA, Najman JM, Plotnikova M, Clavarino AM. Quality of life, age of onset of alcohol use and alcohol use disorders in adolescence and young adulthood: Findings from an Australian birth cohort. Drug Alcohol Rev. juill 2015;34(4):388-96.

61. Solomon MAT, Sabari SOT, Srinivasan B. Correlation between age of alcohol dependence and quality of life - A hospital based cross sectional study. 2018 [cité 14 déc 2020]; Disponible sur: https://imsear.searo.who.int/jspui/handle/123456789/187032 
62. Choi S.W, Na R.H, Kim H.O, Choi S.B, Choi Y.S. The relationship between quality of life and psycho-sociospiritual characteristics in male patients with alcohol dependence. J Korean Neuropsychiatr Assoc. 2006; 45: 459-467.

63. Smith JP, Randall CL. Anxiety and alcohol use disorders: comorbidity and treatment considerations. Alcohol Res. 2012;34(4):414-31.

64. Kushner MG, Maurer E, Menary K, Thuras P. Vulnerability to the rapid ("telescoped") development of alcohol dependence in individuals with anxiety disorder. J Stud Alcohol Drugs. nov 2011;72(6):1019-27.

65. Flensborg-Madsen T, Mortensen EL, Knop J, Becker U, Sher L, Grønbaek M. Comorbidity and temporal ordering of alcohol use disorders and other psychiatric disorders: results from a Danish register-based study. Compr Psychiatry. jul-aug 2009; 50(4):307-14.

66. Regier DA, Rae DS, Narrow WE, Kaelber CT, Schatzberg AF. Prevalence of anxiety disorders and their comorbidity with mood and addictive disorders. Br J Psychiatry Suppl. 1998;(34):24-8.

67. Schneier FR, Foose TE, Hasin DS, Heimberg RG, Liu SM, Grant BF, Blanco C. Social anxiety disorder and alcohol use disorder co-morbidity in the National Epidemiologic Survey on Alcohol and Related Conditions. Psychol Med. jun 2010; 40(6):977-88.

68. Chamberlain SR, Grant JE. Relationship between quality of life in young adults and

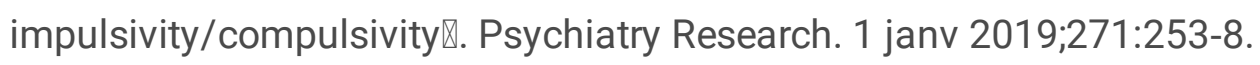

69. Victor SE, Johnson SL, Gotlib IH. Quality of life and impulsivity in bipolar disorder. Bipolar Disord. may 2011;13(3):303-9.

70. Kim YS, Cha B, Lee D, Kim SM, Moon E, Park CS, Kim BJ, Lee CS, Lee S. The Relationship between Impulsivity and Quality of Life in Euthymic Patients with Bipolar Disorder. Psychiatry Investig. sep2013; 10(3):246-52.

71. Shin SH, Hong HG, Jeon S-M. Personality and Alcohol Use: The Role of Impulsivity. Addict Behav. janv 2012;37(1):102-7.

72. Petit G, Cimochowska A, Kornreich C, Hanak C, Verbanck P, Campanella S. Neurophysiological correlates of response inhibition predict relapse in detoxified alcoholic patients: some preliminary evidence from event-related potentials. Neuropsychiatr Dis Treat. 2014;10:1025-37.

73. Salgado JV, Malloy-Diniz LF, Campos VR, Abrantes SSC, Fuentes D, Bechara A, et al. Neuropsychological assessment of impulsive behavior in abstinent alcohol-dependent subjects. Braz J Psychiatry. mars 2009;31(1):4-9.

74. Cabé N, Lanièpce A, Pitel AL. Physical activity: A promising adjunctive treatment for severe alcohol use disorder. Addictive Behaviors. 1 févr 2021;113:106667.

75. Gallo GG, Curado DF, Opaleye ES, Donate APG, Scattone VV, Noto AR. Impulsivity and Mindfulness among Inpatients with Alcohol Use Disorder. Subst Use Misuse. 24 oct 2020;1-8.

\section{Figures}




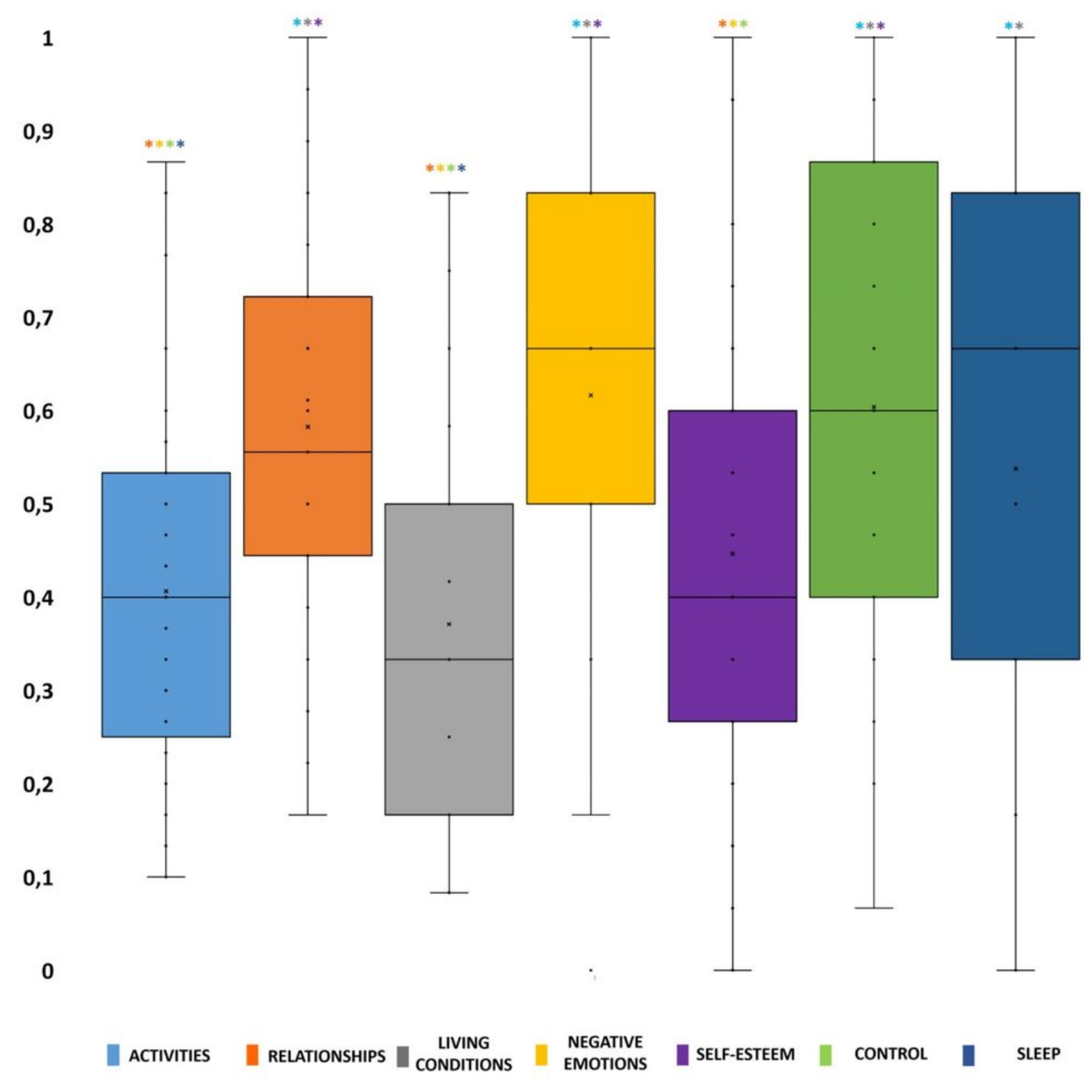

\section{Figure 1}

Normalized domains of HRQoL in recently detoxified sAUD patients. For each boxplot, the median is represented by the bold line and the mean is represented by " $x$ " *: significant difference compared to another domain $(p<0.01)$ using the specific color of each boxplot. 

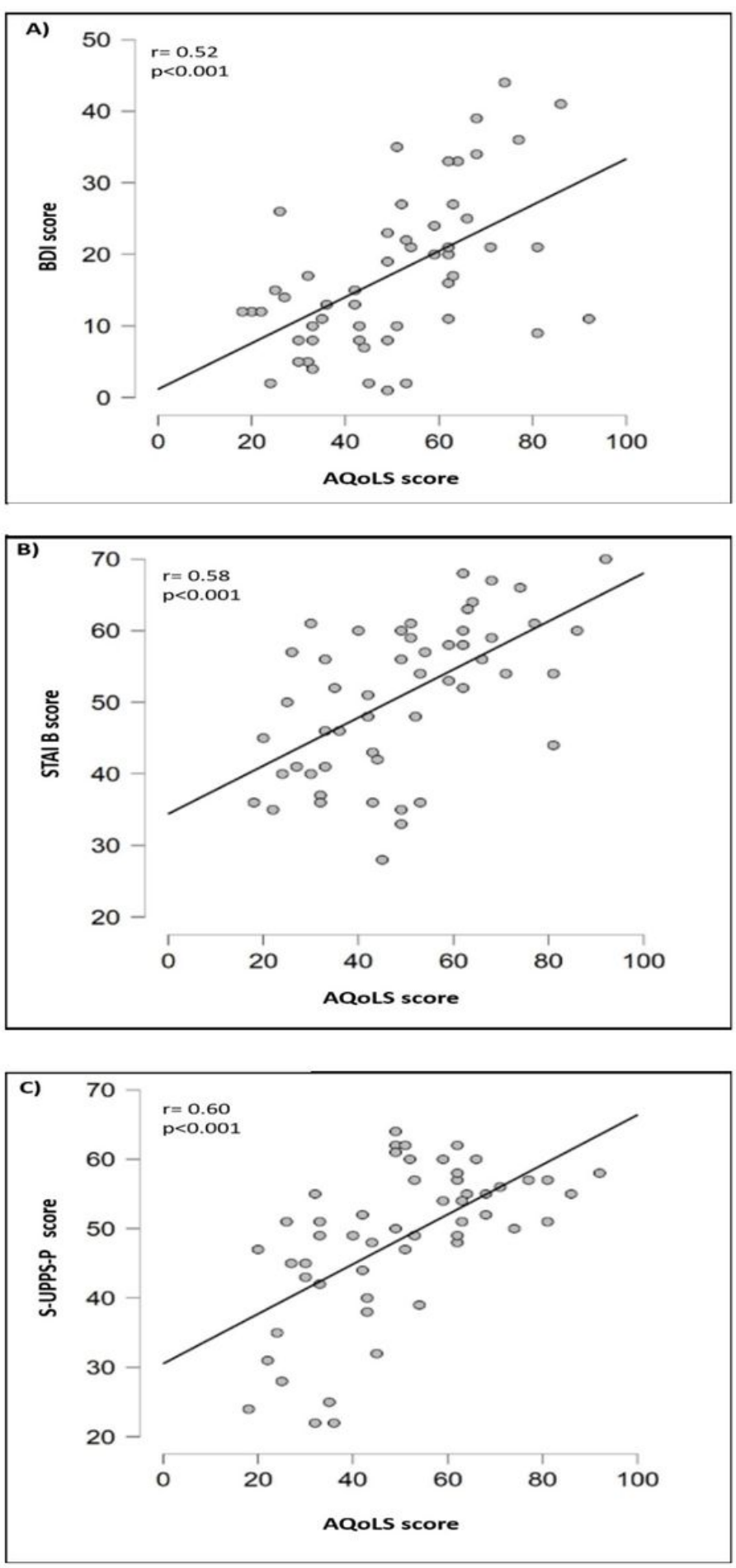

Figure 2

Relationships between HRQoL and A) depression, B) anxiety, and C) impulsivity in recently detoxified sAUD patients. AQoLS: Alcohol Quality of Life Scale; BDI: Beck Depression Inventory; STAI B: State-Trait Anxiety Inventory part B; S-UPPS-P: Short form of- negative Urgency, lack of Premeditation, lack of Perseverance, sensation Seeking, Positive urgency. r: Person's correlation coefficient, * $p<0.01$. 